\title{
ANALISIS DESKRIPTIF FAKTOR-FAKTOR YANG MEMBENTUK PERSEPSI RISIKO PADA STAFF PROYEK Z PT. X
}

\author{
M. Rahmanda Lintang Putranto ${ }^{1}$, Zulkifli Djunaidi ${ }^{2}$ \\ Magister Keselamatan dan Kesehatan Kerja ${ }^{1}$, Departemen Keselamatan dan Kesehatan Kerja \\ Fakultas Kesehatan Masyaratakat, Universitas Indonesia \\ m.rahmanda@ui.ac.id ${ }^{1}$,zul@ui.ac.id ${ }^{2}$
}

\begin{abstract}
The construction sector is one sector that contributes to the occurrence of work accidents, based on the data it recorded that the construction sector contributes to the occurrence of work accidents by $55.2 \%$ in 2020. One of the factors that cause work accidents is the human factor obtained that $70 \%$ of work accidents occur in construction Project $Z s$ due to unsafe acts that are the result of low recognition of hazards and the poor perception of risk related to occupational safety. This study aims to explain an overview of the factors that shape the risk perception on the staff of the construction of PT. X Project $Z$ with the Risk Perceived dimension and socio-cultural dimension approach. The method used is semiquantitative by using a cross-sectional design with the study population is the entire staff on the Project $Z$ PT. $X$ as many as 20 people who will be the respondents. This study uses univariate analysis to describe the frequency distribution of each factor and will be conducted an in-depth analysis of the overview of the frequency distribution. The results showed that of the 10 factors that shape the risk perception of Project $Z$ staff should still be improved, there are 3 factors that become the priority, namely common dread and catastrophic potential, with a value of 1.35 from a scale of 2, and organizational factors with a value of 1.4 form a scale of 2. Management of Project $Z$ is expected to improve the risk perception of Project $Z$ staff in order to be a role model for workers and prevent the occurrence of work accidents.
\end{abstract}

Keywords $\quad$ : Safety, Risk Perception, Staff Construction

\begin{abstract}
ABSTRAK
Sektor konstruksi merupakan salah satu sektor yang menyumbang terjadinya kecelakaan kerja, berdasarkan data tercatat bahwa sektor konstruksi menyumbang terjadinya kecelakaan kerja sebesar $55,2 \%$ pada tahun 2020. Salah satu faktor yang menyebabkan terjadinya kecelakaan kerja adalah faktor manusia didapatkan bahwa 70\% kecelakaan kerja terjadi di Proyek konstruksi karena tindakan tidak aman yang merupakan hasil dari rendahnya rekognisi bahaya dan buruknya persepsi risiko terkait keselamatan kerja. Penelitian ini bertujuan untuk menjelaskan gambaran faktor-faktor yang membentuk persepsi risiko pada staff konstruksi PT. X Proyek Z dengan pendekatan dimensi risk perceived dan dimensi sosial budaya. Metode yang digunakan adalah semi kuantitaif dengan menggunakan rancangan cross sectional dengan populasi penelitian ialah seluruh staff pada Proyek Z PT. X sebanyak 20 orang yang akan menjadi responden. Penelitian ini menggunakan analisis univariat untuk menggambarkan distribusi frekuensi masing-masing faktor dan dilakukan analisis mendalam dari gambaran distribusi frekuensi. Hasil penelitian menunjukan bahwa dari 10 faktor yang membentuk persepsi risiko staff Proyek $\mathrm{Z}$ masih harus ditingkatkan, terdapat 3 faktor yang menjadi prioritas yaitu faktor common dread dan catastrophic potential, dengan nilai 1,35 dari skala 2, lalu faktor organisasi dengan nilai 1,4 dari skala 2. Manajemen Proyek $\mathrm{Z}$ diharapkan mampu meningkatkan persepsi risiko staff Proyek $\mathrm{Z}$ agar dapat menjadi role model untuk para pekerja dan mencegah terjadinya kecelakaan kerja.
\end{abstract}

Kata Kunci $\quad$ : Sektor Konstruksi, Staff Proyek, Persepsi Risiko

\section{PENDAHULUAN}

Sektor konstruksi merupakan salah satu sektor yang menyumbang terjadinya kecelakaan kerja, berdasarkan data tercatat bahwa sektor konstruksi menyumbang terjadinya kecelakaan kerja sebesar $55,2 \%$ pada tahun 2020. Tingginya kecelakaan pada sektor konstruksi disebabkan oleh beberapa faktor (Alomari et al., 2018). Salah satu faktor yang mempengaruhi 
adalah faktor manusia, sebagai contoh didapatkan bahwa $70 \%$ kecelakaan kerja yang terjadi di Proyek konstruksi disebabkan karena tindakan tidak aman (Haslam et al., 2005), tindakan tidak aman dapat terjadi bukan karena adanya violation namun merupakan hasil dari rendahnya rekognisi terhadap bahaya dan buruknya persepsi risiko terkait keselamatan dari pekerja/staff konstruksi (Tixier et al. 2013).

Persepsi risiko merupakan hasil dari seseorang merekognisi suatu bahaya lalu menentukan risiko dari bahaya tersebut (Slovic \& Weber, 2002), maka dari itu persepsi risiko akan berbeda dari setiap orang baik pekerja, staff, maupun expert di bidang safety, risiko dapat digunakan untuk merekognisi hazard, melihat probability, severity, atau sebuah ancaman (Slovic \& Weber, 2002). Persepsi risiko merupakan hal yang penting untuk mencegah terjadinya kecelakaan kerja, selain kemampuan persepsi risiko hal pertama yang menjadi penting adalah kemampuan merekognisi bahaya, apabila hazard tidak terekognisi, maka risiko tidak akan dirasakan oleh pekerja atau staff, sehingga tidak akan ada upaya untuk mencegah terjadinya kecelakaan kerja (Albert et al., 2014). Apabila bahaya telah terekognisi, persepsi risiko setiap orang menjadi penting untuk merasakan risiko dari bahaya yang telah terekognisi, apabila risiko sudah dirasakan maka akan terdapat tindakan untuk mencegah terjadinya kecelakaan kerja (Namian et al., 2016). Namun, salah satu studi menunjukan bahwa permasalahan pada sektor konstruksi ialah meskipun bahaya sudah direkognisi, namun risiko masih dianggap sesuatu yang tidak serius sehingga risiko tersebut cenderung diabaikan sehingga tidak ada upaya untuk mencegah terjadinya kecelakaan kerja (Shin et al., 2014).

Terdapat beberapa pendekatan untuk melakukan analisis persepsi risiko, yaitu paradigma risk perceived dan paradigma sosial budaya (Loewenstein et al., 2001). Persepsi risiko dari sudut pandang risk perceived berpendapat bahwa risiko adalah hal yang bersifat subjektif, ini merupakan hasil dari kemampuan setiap subjek melakukan rekognisi bahaya (Sjöberg et al., 2004). Dimensi risk perceived persepsi risiko yang dilakukan dalam studi Sjoberg et al, (2004) ialah voluntariness of risk, immediacy of effect, knowledge of risk, control of risk, catastrophic potential, common dread, severity of consequences. Persepektif risk perceived dapat mengarah pada sesuatu yang berharga untuk menentukan persepsi risiko seseorang sehingga dapat menjadi masukan untuk manajemen dalam meningkatkan persepsi risiko seluruh personil (McGonagle \& Kath, 2010). Studi persepsi risiko dalam paradigma sosial budaya melihat bagaimana kelompok kerja dan budaya organisasi dapat mempengaruh persepsi risiko seseorang (Slovic \& Weber, 2002). Studi dari (Namian et al., 2016) menunjukan bahwa tingginya penerapan training akan berdampak pada meningkatnya persepsi risiko dari kelompok kerja, hal ini menjelaskan bahwa training merupakan faktor untuk penting untuk meningkatkan persepsi risiko dari kelompok kerja. Adanya peraturan terkait safety yang berlaku dan tingkat kepatuhan dan keterlibatan seluruh pihak akan berdampak pada baiknya record terkait safety termasuk tingkat persepsi risiko dari seluruh personel yang ada di area kerja (Martin \& Lewis, 2014).

Berdasarkan literatur yang telah dijelaskan, maka penelitian ini akan menganalisis faktor-faktor yang membentuk persepsi risiko pada staff Proyek konstruksi dengan pendekatan risk perceived dengan faktor voluntariness of risk, immediacy of effect, knowledge of risk, control of risk, catastrophic potential, common dread, severity of consequences, selanjutnya dengan pendekatan sosial budaya dengan faktor training, regulatory, dan organization.

Berdasarkan dari literatur yang telah dijelaskan, dapat dilihat bahwasanya konstruksi merupakan salah satu sektor yang menyumbang terjadinya kecelakan 
kerja, buruknya persepsi risiko merupakan salah satu faktor tingginya tingkat kecelakaan pada sektor konstruksi. Terdapat dua pendekatan untuk menganalisis persepsi risiko yaitu dengan dimensi risk perceived dan sosial budaya. Tujuan dari penelitian ini untuk menjelaskan gambaran faktor-faktor yang membentuk persepsi risiko pada staff konstruksi Proyek Z PT. X, sehingga hasil dari penelitian dapat digunakan untuk PT. $\mathrm{X}$ dalam mengembangkan program untuk meningkatkan persepsi risiko seluruh staff yang ada di PT. X.

\section{METODE}

Penelitian ini merupakan penelitian semi kuantitaif dengan menggunakan rancangan cross sectional dengan populasi penelitian ialah seluruh staff pada Proyek Z PT. $X$ yang merupakan salah satu kontraktor Gedung bertingkat terbesar yang ada di Indonesia, pengambilan data dilakukan menggunakan kuesioner. Kuesioner yang digunakan merupakan hasil pengembangan dari faktor-faktor yang membentuk persepsi risiko yang telah dilakukan pada penelitian lain sehingga didapatkan 10 variabel yang digunakan dalam kuesioner ini, kuesioner telah melewati tes validitas dan reliabilitas menggunakan SPSS dan telah dinyatakan valid dan reliable. Responden mengisi kuesioner dengan skala likert dari 1 sampai 4, (1=Sangat tidak setuju, 2= Tidak setuju, $3=$ Setuju, 4= Sangat setuju) untuk masing masing variabel. Pengambilan data dilakukan pada tanggal 26 April 2021. Jumlah responden sebanyak 20 orang yang merupakan jumlah seluruh staff yang ada pada Proyek Z PT. X, data akan dianalisis secara univariat untuk mengetahui gambaran masing-masing variabel yang diteliti. Data yang dianalisis selanjutnya akan disajikan dalam bentuk tabel untuk memberikan gambaran distribusi frekuensi faktor-faktor yang mempengaruhi persepsi risiko menggunakan IBM SPSS Versi 25.
HASIL

\begin{tabular}{|c|c|c|c|}
\hline Tabel & $\begin{array}{l}\text { 1. Hasil } \\
\text { Karakteristik } \\
\text { Repsonden }\end{array}$ & Analisis & $\begin{array}{r}\text { Univariat } \\
\text { Demografi }\end{array}$ \\
\hline & $\begin{array}{l}\text { arakteristik } \\
\text { Demografi }\end{array}$ & $\mathrm{N}$ & $(\%)$ \\
\hline \multicolumn{4}{|c|}{ Jenis Kelamin } \\
\hline Laki-I & & 19 & 95 \\
\hline Perem & buan & 1 & 5 \\
\hline \multicolumn{4}{|l|}{ Usia } \\
\hline$<30$ & & 5 & 25 \\
\hline$>31$ & & 15 & 75 \\
\hline \multicolumn{4}{|c|}{ Lama Kerja } \\
\hline $1-3 \mathrm{Bt}$ & & 4 & 20 \\
\hline $3-6 \mathrm{Bt}$ & & 16 & 80 \\
\hline
\end{tabular}

Hasil distribusi karakteristik frekuensi demografi responden (Tabel 1) menunjukan bahwa mayoritas responden adalah laki-laki yaitu sebesar (95\%), lalu untuk sebaran usia didapatkan bahwa staff dari Proyek Z PT. X yaitu sebanyak 15 orang $(75 \%)$ berusia $>31$ tahun, sedangkan sebanyak 5 orang $(20 \%)$ berusia $<30$ tahun. Untuk lama bekerja staff PT. X di Proyek Z didapatkan sebaran bahwa staff yang bekerja 3-6 Bulan sebanyak 16 orang $(80 \%)$, lalu didapatkan staff yang bekerja 13 Bulan sebanyak 4 orang (20\%), hal ini disebabkan karena Proyek $\mathrm{Z}$ memang baru berjalan selama 6 bulan, untuk jumlah responden sebanyak 20 orang yang merupakan total dari seluruh staff yang ada di Proyek Z PT. X.

Tabel 2. Distribusi Frekuensi Pemahaman Responden terkait Training

\begin{tabular}{|c|c|c|}
\hline Training & $\mathrm{N}$ & $(\%)$ \\
\hline $\begin{array}{ll}\text { Training } & \text { Kurang } \\
\text { Penting } & \end{array}$ & 10 & 50 \\
\hline Training Penting & 10 & 50 \\
\hline
\end{tabular}

Berdasarkan tabel 2 didapatkan bahwa pemahaman staff Proyek Z PT. X terkait training, terdapat 10 orang $(50 \%)$ yang menganggap training adalah hal yang kurang penting, sedangkan didapatkan 10 orang $(50 \%)$ menganggap bahwa training merupakan hal yang penting.

Tabel 3. Distribusi Frekuensi Pemahaman Responden terhadap Regulatory 
(Peraturan) terkait safety yang berlaku di PT. $X$

\begin{tabular}{lcc}
\hline \multicolumn{1}{c}{ Regulatory } & $\mathrm{N}$ & $(\%)$ \\
\hline Kurang Baik & 10 & 50 \\
Baik & 10 & 50
\end{tabular}

Berdasarkan tabel 3 didapatkan bahwa pemahaman staff Proyek Z PT. X terkait peraturan terkait safety yang berlaku di PT. $\mathrm{X}$, terdapat 10 orang $(50 \%)$ yang masih kurang baik pemahamannya, dan didapatkan 10 orang (50\%) yang sudah baik pemahamannya.

Tabel 4. Distribusi Frekuensi Pemahaman Responden terhadap Peran Organisasi

\begin{tabular}{lcc}
\hline \multicolumn{1}{c}{ Regulatory } & $\mathrm{N}$ & $(\%)$ \\
\hline Kurang Baik & 12 & 60 \\
\hline Baik & 8 & 40
\end{tabular}

Berdasarkan tabel 4 didapatkan bahwa pemahaman staff Proyek Z PT. X terkait peran organisasi terdapat 12 orang $(60 \%)$ yang masih kurang baik pemahamannya terhadap peran yang dilakukan oleh organisasi, dan 8 orang $(40 \%)$ yang sudah baik pemahamannya.

Tabel 5. Distribusi Frekuensi Tingkat Voluntariness of Risk Responden terhadap Risiko

\begin{tabular}{lcc}
\multicolumn{1}{c}{ Regulatory } & $\mathrm{N}$ & $(\%)$ \\
\hline Terpaksa & 11 & 55 \\
& & \\
\hline Sukarela & 9 & 45
\end{tabular}

Berdasarkan tabel 5 didapatkan bahwa terdapat 11 orang (55\%) dari staff Proyek Z yang merasa terpaksa untuk menerima risiko yang ada pada pekerjaan, dan didapatkan 9 orang (45\%) staff Proyek Z merasa sukarela terhadap risiko yang ada pada pekerjaan.

Tabel 6. Distribusi Frekuensi Tingkat immediacy of effect yang dirasakan oleh Responden

\begin{tabular}{lcc}
\hline \multicolumn{1}{c}{ Regulatory } & $\mathrm{N}$ & $(\%)$ \\
\hline Tidak Langsung & 12 & 60 \\
\hline Langsung & 8 & 40
\end{tabular}

Berdasarkan tabel 6 didapatkan bahwa terdapat 12 orang (60\%) dari staff Proyek Z yang merasa bahwa suatu risiko tidak menyebabkan efek langsung, sedangkan didapatkan 8 orang (40\%) staff Proyek Z yang merasa bahwa suatu risiko bisa menyebabkan efek langsung.

Tabel 7. Distribusi Frekuensi Tingkat Knowledge of Risk oleh Responden

\begin{tabular}{lcc}
\hline \multicolumn{1}{c}{ Regulatory } & $\mathrm{N}$ & $(\%)$ \\
\hline Kurang baik & 12 & 60 \\
Baik & 8 & 40 \\
\hline
\end{tabular}

Berdasarkan tabel 7 didapatkan bahwa terdapat 12 orang (60\%) dari staff Proyek Z memiliki pengetahuan yang kurang baik terhadap risiko, sedangkan didapatkan didapatkan 8 orang (40\%) staff Proyek Z yang sudah baik pengetahuannya terhadap risiko.

Tabel 8. Distribusi Frekuensi Tingkat Control of Risk oleh Responden

\begin{tabular}{lcc}
\hline \multicolumn{1}{c}{ Regulatory } & N & $(\%)$ \\
\hline Kurang baik & 11 & 55 \\
Baik & 9 & 45
\end{tabular}

Berdasarkan tabel 8 didapatkan bahwa terdapat 11 orang (55\%) dari staff Proyek Z kurang baik dalam pengendalian risiko, sedangkan didapatkan didapatkan 9 orang (45\%) staff Proyek Z yang bisa melakukan control terhadap pengendalian risiko.

Tabel 9. Distribusi Frekuensi Catastrophic Potential oleh Responden

\begin{tabular}{lcc}
\hline \multicolumn{1}{c}{ Regulatory } & $\mathrm{N}$ & $(\%)$ \\
\hline Katastropik & 7 & 35 \\
Kronik & 13 & 65
\end{tabular}

Berdasarkan tabel 9 didapatkan bahwa terdapat 7 orang (35\%) dari staff Proyek Z menilai dampak dari suatu risiko bersifat katastropik, sedangkan didapatkan didapatkan 13 orang (65\%) staff Proyek Z menilai dampak dari suatu risiko bersifat kronik. 
Tabel 10. Distribusi Frekuensi Common dread oleh Responden

\begin{tabular}{lcc}
\hline \multicolumn{1}{c}{ Regulatory } & $\mathrm{N}$ & $(\%)$ \\
\hline Tidak takut & 13 & 65 \\
\hline Takut & 7 & 35
\end{tabular}

Berdasarkan tabel 10 didapatkan bahwa terdapat 13 orang (65\%) dari staff Proyek Z tidak takut dalam menghadapi risiko yang ada pada pekerjaan, sedangkan didapatkan didapatkan 7 orang (35\%) staff Proyek Z takut dalam menghadapi risiko yang ada pada pekerjaan.

Tabel 11. Distribusi Frekuensi Severity of Consequences oleh Responden

\begin{tabular}{lcc}
\hline \multicolumn{1}{c}{ Regulatory } & N & $(\%)$ \\
\hline Kurang Fatal & 10 & 50 \\
\hline Fatal & 10 & 50
\end{tabular}

Berdasarkan tabel 11 didapatkan bahwa terdapat 10 orang (50\%) dari staff Proyek Z merasa konsekuensi dari suatu risiko bersifat kurang fatal, sedangkan didapatkan didapatkan 10 orang (50\%) staff Proyek Z merasa konsekuensi dari suatu risiko bersifat fatal.

\section{PEMBAHASAN}

\section{Faktor Training}

PT. X telah memiliki Departemen khusus yang mengontrol terkait pelaksanaan training (Departemen Training), termasuk training terkait safety kepada seluruh staff PT. X, pelaksanaan training yang dilakukan oleh Departemen Training hanya sekedar teori, belum ada materi training terkait safety yang dilakukan oleh Departemen Training yang dilakukan secara praktik di lapangan. HSE Plan yang dimiliki oleh Proyek $\mathrm{Z}$ didapatkan bahwa tidak ada pembahasan khusus terkait training yang akan dilakukan untuk staff Proyek $\mathrm{Z}$ yang diselenggarakan oleh HSE Proyek Z, hal ini menunjukan bahwa training untuk staff Proyek $\mathrm{Z}$ seluruhnya diserahkan kepada Departemen Training.

Apabila dilihat dari gambaran responden terkait training yang masih rendah dalam studi ini, maka diperlukan beberapa rekomendasi untuk meningkatkan pemahaman terkait training, berdasarkan penelitian yang dilakukan oleh Namian (2016) bahwa pelaksanaan metode training yang baik (terdapat expert yang memberikan training, terjadi interaksi yang baik antara peserta training dan trainer, training dilaksanakan di lapangan (on site) dan di dalam kelas untuk pemberian materi) dapat meningkatkan pemahaman pentingnya training dan berujung pada meningkatnya persepsi risiko. Hasil penelitian oleh Namian (2016) dapat menjadi salah satu referensi rekomendasi untuk meningkatkan kualitas training yang telah dilakukan oleh Departemen Training. Selain itu Proyek juga dapat melaksanakan training untuk staff Proyek $\mathrm{Z}$ yang dilaksanakan secara mandiri oleh Proyek, kebutuhan terkait training dapat dicantumkan pada dokumen HSE Plan Proyek Z.

\section{Faktor Regulatory}

PT. X telah memiliki beberapa prosedur yang berkaitan dengan Safety, di antaranya Kebijakan yang telah ditanda tangani oleh Presiden Direktur dari PT. X, lalu P-22 yaitu prosedur yang mengatur terkait sistem Safety yang ada di seluruh Proyek PT. X, HSE Plan, yang merupakan dokumen khusus terkait pelaksanaan penerapan program Safety untuk Proyek Z, Dokumen Ijin Kerja, HIRADC dan JSEA. Dokumen terkait safety yang dimiliki oleh Proyek Z PT. X telah baik, namun dari studi ini dapat dilihat bahwa masih terdapat $50 \%$ staff Proyek $\mathrm{Z}$ yang belum memahami terkait peraturan yang berlaku di PT. X

Berdasarkan penelitian yang dilakukan oleh Alomari et al., (2018) didapatkan bahwa regulatory atau peraturan terkait safety yang berlaku pada suatu tempat kerja akan mempengaruhi persepsi orang-orang yang ada di dalamnya. Maka dari itu untuk 
meningkatkan pemahaman terkait peraturan yang berlaku terkait Safety menurut penelitian yang dilakukan oleh Martin H., Lewis (2003), ialah melibatkan banyak pihak untuk terlibat dalam safety, HSE Proyek dapat melakukan komunikasi secara berkala terkait peraturan yang berlaku kepada seluruh staff Proyek Z, setelah itu seluruh staff Proyek Z dapat melibatkan seluruh pekerja agar dapat mengetahui peraturan yang berlaku terkait safety, selanjutnya adalah Komunikasi, seluruh peraturan yang telah dimiliki oleh PT. X harus dikomunikasikan kepada seluruh staff terkhusus kepada staff Proyek $\mathrm{Z}$, setelah itu staff Proyek Z mengkomunikasikannya kepada seluruh pekerja.

\section{Faktor Organization}

PT. X telah memiliki upaya untuk membentuk budaya terkait K3 di seluruh Proyek PT. X, beberapa upaya yang telah dilakukan oleh PT. $X$ ialah adanya komitmen dari pimpinan manajemen untuk menciptakan lingkungan kerja yang terkendali, program komunikasi terkait safety seperti Toolbox Meeting (TBM), dan Safety Talk yang dilakukan secara berkala, Campaign K3, dan Reward untuk pekerja yang patuh terhadap penerapan safety. Selain itu juga PT. X telah tersertifikasi ISO 45001 dan Sistem Manajemen Keselamatan dan Kesehatan Kerja (SMK3).

Berdasarkan penelitian yang dilakukan oleh Alomari et al., (2018) bahwa faktor organisasi seperti komitmen manajemen, penerapan program terkait safety, budaya terkait safety merupakan faktor penting untuk meningkatkan persepsi risiko seseorang di tempat kerja. Perilaku seorang pekerja bekerja dengan aman juga dipengaruhi oleh komunikasi yang diterima, improvement dari organisasi untuk meningkatkan awareness dari seluruh staff berpengaruh untuk meningkatkan pemahaman risiko dan berujung pada mencegah terjadinya kecelakaan kerja (Guertler et al., 2021). Namun berdasarkan studi penelitian ini didapatkan bahwa masih terdapat 12 orang (60\%) staff yang kurang pemahamannya terkait peran organisasi terhadap safety, untuk program seperti campaign $\mathrm{K} 3$ dan reward Proyek $\mathrm{Z}$ dapat melakukan perencanaan yang lebih spesifik agar pelaksanaannya dapat terlaksana dengan terencana dan dampaknya bisa dirasakan, untuk reward sampai dengan saat ini diberikan hanya kepada pekerja, belum ada reward khusus dari Proyek $\mathrm{Z}$ untuk staff yang telah menjadi contoh dalam penerapan K3. Selain itu program komunikasi terkait K3 masih minim pemberiannya kepada staff, masih berfokus pada para pekerja.

\section{Faktor Voluntariness of Risk}

Masih terdapat subkontraktor dan mandor yang belum memiliki dokumen perencanaan terkait $\mathrm{K} 3 \mathrm{~L}$, hal ini menjadi indikasi bahwasanya subkontraktor dan mandor belum melakukan perencanaan yang terstruktur terkait pengendalian risiko yang timbul dari pekerjaan, hal ini pun menjadi catatan bagi staff Proyek Z PT. X sebagai main kontraktor yang memperbolehkan subkontraktor dan mandor bekerja sebelum adanya perencanaan terkait dokumen K3L melalui Rencana Pelaksanaan Subkontraktor (RPS), didapatkan juga bahwa mandor yang bekerja tidak ada kewajiban untuk membuat RPS, hanya subkontraktor yang memiliki kewajiban membuat RPS. Dari data penelitian menggambarkan bahwa terdapat $55 \%$ staff Proyek Z merasa terpaksa terhadap risiko yang timbul dari pekerjaan, lemahnya perencanaan terkait K3L menjadi salah satu pendukung mengapa masih tinggi persentase orang yang terpaksa untuk menghadapi risiko yang ada pada pekerjaan.

Hasil penelitian menunjukan terdapat $45 \%$ staff Proyek $\mathrm{Z}$ merasa sukarela terhadap risiko yang ada pekerjaan, sukarela di sini memiliki beragam arti, dapat diartikan sukarela menghadapi risiko karena risiko yang timbul telah dilakukan pengendalian sehingga risiko dapat diterima, atau adanya sikap tidak peduli 
dengan risiko yang ada pada pekerjaan. Faktor yang sering muncul dalam kasus unsafe act adalah pengambilan risiko secara sukarela, individu merasa lebih nyaman dengan pengambilan risiko secara sukarela karena merasa memegang kendali (Starr, 1969). Studi tersebut dapat menjadi perhatian oleh tim Proyek, karena berdasarkan hasil telaah dokumen yang dilakukan terdapat beberapa kondisi berisiko yang belum dilakukan pengendalian.

\section{Faktor Immediacy of Effect}

Proyek $\mathrm{Z}$ telah berjalan selama 5 bulan sejak saat pengambilan data terkait persepsi risiko ke seluruh staff Proyek Z, sampai dengan 5 bulan berjalannya Proyek, Proyek $\mathrm{Z}$ belum mengalami kecelakaan kerja, baik itu MTI, LTI, ataupun Fatality. Apabila dilihat dari data inspeksi, didapatkan bahwa banyak pengendalian risiko yang belum dilakukan oleh staff Proyek, seperti tidak adanya platform kerja untuk pekerjaan di ketinggian, tidak tersedia Apron untuk pekerjaan panas. Namun berdasarkan data didapatkan bahwa terdapat 12 orang $(60 \%)$ staff Proyek $\mathrm{Z}$ yang merasa bahwa risiko yang ada pada pekerjaan berdampak tidak langsung atau delay, hal ini dapat didukung karena Proyek belum pernah merasakan dalam kondisi ketika telah terjadi kecelakaan kerja, sehingga persepsi terkait immediacy of effect masih terdapat $60 \%$ orang yang menganggap bahwa dampak dari risiko akan terjadi delay.

Faktor Immediacy of effect memiliki pengaruh terhadap penilaian risiko seseorang (Holmes et al., 1999). Penelitian yang dilakukan oleh Lingard (2005) menunjukan bahwa pengendalian risiko yang memiliki dampak langsung atau jangka panjang memiliki pendekatan pengendalian yang berbeda. Maka dari itu faktor ini menjadi perhatian oleh staff Proyek Z untuk dapat meningkatkan persepsi terhadap suatu risiko, mengingat risiko yang ada di Proyek konstruksi banyak yang memiliki dampak secara langsung. Penilaian terhadap Immediacy of effect dapat ditingkatkan oleh tim Proyek dengan cara mengikuti kegiatan inspeksi, pembahasan terkait hasil inspeksi, dan juga melakukan penilaian risiko pekerjaan.

\section{Faktor Knowledge of Risk}

Proyek Z telah memiliki program untuk mengidentifikasi risiko pada pekerjaan, seperti pembuatan dokumen Risk Control Self-Assessment (RCSA), dokumen ini merupakan dokumen awal identifikasi risiko terkait $\mathrm{K} 3$ yang mungkin timbul dari aktivitas Proyek. Selain itu tersedia dokumen Hazard Identification and Determining Control (HIRADC), merupakan dokumen identifikasi risiko yang timbul pada suatu pekerjaan. Namun data penelitian menunjukan terdapat 12 orang (60\%) staff Proyek Z yang memiliki pengetahuan kurang baik terkait risiko pada pekerjaan, hal ini dapat disebabkan karena pembuatan dokumen terkait risiko hanya melibatkan beberapa bagian dari staff Proyek Z, sehingga memungkinkan tidak semua staff Proyek Z memiliki pengetahuan yang baik terkait risiko, selain itu tidak terdapat dokumentasi yang menunjukan bahwa dokumen terkait identifikasi risiko ini dikomunikasikan kepada seluruh staff Proyek Z.

Dapat penelitian yang menunjukan $60 \%$ staff Proyek $\mathrm{Z}$ memiliki pengetahuan kurang baik terkait risiko juga sejalan dengan hasil analisis faktor training pada penelitian ini yang menunjukan belum adanya perencanaan pelatihan yang dilakukan oleh Proyek yang ditujukan untuk staff Proyek Z. Mayoritas pengetahuan tentang risiko didapatkan dari Proyek-Proyek yang pernah dikerjakan (Maqsood, 2015) hal ini menjadi perhatian karena apabila pengetahuan tentang risiko hanya diserahkan pada pengalaman, maka pengetahuan tentang risiko akan menjadi tidak merata, oleh karena itu penerapan manajemen pengetahuan risiko dapat diterapkan untuk sektor konstruksi (Carrillo \& Chinowsky, 2006). 


\section{Faktor Control of Risk}

Proyek $\mathrm{Z}$ telah memiliki program untuk memastikan pekerja memahami untuk mengendalian risiko yang muncul pada pekerjaan, di antaranya adalah program TBM, pada saat pelaksanaan TBM Proyek Z yang diwakili oleh Quality supervisor (Qspv) atau Site Manager (SM) akan menyampaikan pengendalian risiko yang ada pada pekerjaan, selanjutnya terdapat training secara berkala dari staff Proyek $\mathrm{Z}$ terkait pengendalian risiko, namun berdasarkan data terdapat 55\% dari staff Proyek $\mathrm{Z}$ yang masih kurang baik pemahamannya untuk control of risk, hal ini dapat dimungkinkan bahwa yang memahami pengendalian risiko hanya bagian bagian tertentu seperti $\mathrm{SM}$ atau Qspv, sedangkan staff lainnya belum memahami proses, risiko, dan pengendalian terkait risiko yang ada pada pekerjaan. Hal ini dapat diperkuat dengan tidak adanya pelatihan untuk staff Proyek $\mathrm{Z}$ terkait pengendalian risiko yang ada pada pekerjaan, sehingga membentuk rendahnya persepsi staff Proyek Z untuk faktor control of risk. Terdapat studi yang menunjukan bahwa faktor control of risk memiliki pengaruh yang signifikan terhadap persepsi risiko, maka dari itu diperlukan peningkatan pengetahuan terkait pengendalian risiko untuk meningkatkan persepsi risiko (Chaswa et al., 2020).

\section{Faktor Catastrophic Potential}

Proyek Z memiliki beberapa pekerjaan yang dapat menyebabkan kecelakaan lebih dari satu orang (katastropik) seperti pekerjaan pengangkatan baja, pada proses pekerjaan pengangkatan baja berpotensi untuk menyebabkan lebih dari satu orang menjadi korban apabila terjadi kegagalan pengangkatan baja. Selain itu risiko yang tertulis di RCSA memang lebih banyak yang berpotensi menyebabkan kecelakaan pada pekerja tersebut saja, seperti pekerjaan di ketinggian dan pekerjaan listrik. Hasil penelitian yang menunjukan 13 orang (65\%) menganggap bahwa Catastrophic Potential bersifat kronik hal ini sesuai dengan data risiko yang tercatat pada dokumen RCSA yang menjelaskan memang risiko yang ada pada Proyek $\mathrm{Z}$ lebih mengancam keselamatan pekerja yang melakukan pekerjaan tersebut saja. Namun studi lain menunjukan bahwa terdapat perbedaan pandangan antara orang yang memiliki keahlian khusus atau teknisi dengan orang awam terhadap faktor catastrophic potential dapat dimungkinkan hasil studi yang menunjukan terdapat $65 \%$ staff Proyek $\mathrm{Z}$ yang menganggap risikonya bersifat kronik karena lemahnya kemampuan staff Proyek $\mathrm{Z}$ dalam menilai risiko (Schmidt, 2004), sehingga masih terdapat beberapa risiko yang bersifat katastropik namun belum teridentifikasi.

\section{Faktor Common dread}

Terdapat beberapa pekerjaan yang memiliki risiko hingga menyebabkan fatality, namun didapatkan masih terdapat subkontraktor atau mandor yang belum memiliki dokumen rencana pengendalian program K3, hal ini dibuktikan bahwa masih rendah perencanaan program K3 untuk setiap subkontraktor dan mandor. Dari data inspeksi yang dilakukan oleh tim Proyek $\mathrm{Z}$ menunjukan masih banyak kondisi bahaya yang belum dilakukan pengendalian. Hal ini dapat menjadi indikasi bahwa tingginya rasa tidak takut oleh staff Proyek Z yaitu sebesar 65\%, bukan karena tidak ada kondisi yang berisiko tinggi atau risiko sudah dilakukan pengendalian, melainkan karena kurangnya persepsi rasa takut terhadap kondisi bahaya, sehingga sudah terbiasa dengan kondisi yang tidak aman, sekalipun kondisi tersebut memiliki risiko yang dapat menyebabkan fatality. Selain itu faktor common dread juga terbentuk karena kejadian yang pernah terjadi pada masing-masing personil, sehingga terdapat kemungkinan akan terdapat personil yang meremehkan risiko yang dianggapnya kurang besar (Slovic et al., 1980). Hasil penelitian yang dilakukan 
oleh Lichtenstein juga diperkuat berdasarkan data yang menunjukan bahwa Proyek $\mathrm{Z}$ belum pernah terjadi kecelakaan kerja yang bersifat Medical Treatment Injury sampai dengan Fatality.

\section{Faktor Severity of Consequences}

Proyek $\mathrm{Z}$ memiliki risiko pekerjaan yang dapat menyebabkan fatality. Berdasarkan dokumen HIRADC, masih terdapat beberapa pekerjaan yang belum tersedia HIRADC, dan dokumen HIRADC belum pernah diupdate sejak pertama kali Proyek berjalan hal ini menunjukan penilaian terhadap risiko tidak dilakukan secara berkala.

Faktor severity of consequences menjadi penting untuk diperhatikan karena sektor konstruksi merupakan sektor yang memiliki risiko tinggi yang dapat menyebabkan fatality, persepsi risiko secara umum apabila dapat dibayangkan maka akan meningkatkan pemahaman kita terkait severity of consequences, sebaliknya jika dampak yang dapat dibayangkan tidak langsung cenderung pemahaman terkait severity of consequences rendah (Wilson et al., 2019). Berdasarkan penelitian ini didapatkan terdapat 50\% staff Proyek Z yang menganggap severity of consequences yang ada pada pekerjaan konstruksi tidak fatal, hal ini dapat menjadi perhatian karena rendahnya pemahaman terkait severity of consequences dapat mengakibatkan lalainya manajemen Proyek dalam mengendalikan risiko yang ada pada pekerjaan sehingga berujung pada terjadinya accident.

\section{Diagram Jaring Faktor-Faktor yang Membentuk Persepsi Risiko}

Dari hasil studi ini menunjukan bahwa masing-masing faktor yang membentuk persepsi risiko untuk staff Proyek Z PT. X masih rendah, sehingga perlu ditingkatkan agar dapat membentuk persepsi risiko yang baik. Berdasarkan Grafik 1, berikut adalah faktor yang menjadi prioritas untuk perbaikan yang dapat dilakukan oleh staff Proyek Z.

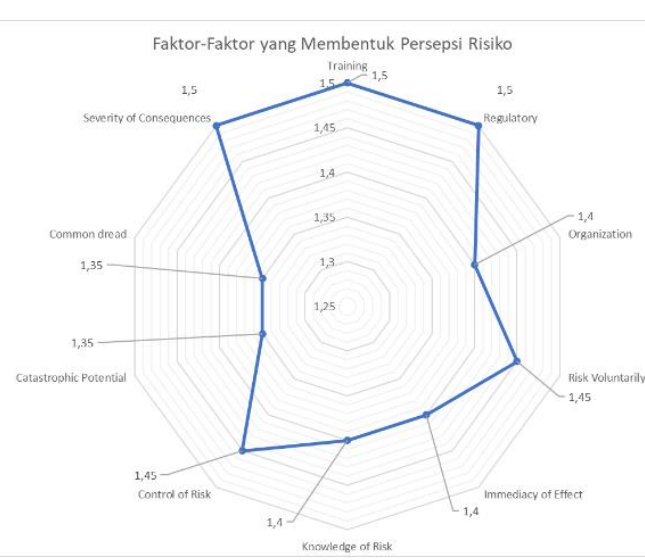

Grafik 1. Faktor-Faktor yang Membentuk Persepsi Risiko

Didapatkan bahwa untuk dimensi risk perceived yang menjadi prioritas adalah faktor common dread dan catastrophic potential, dengan nilai 1,35 dari skala 2 . Untuk dimensi sosial budaya faktor organisasi menjadi prioritas dengan nilai 1,4 dari skala 2. Pembahasan masingmasing faktor telah dibahas pada point pembahasan sebelumnya, grafik ini dapat menjadi gambaran untuk manajemen Proyek $\mathrm{Z}$ faktor yang menjadi prioritas untuk dikembangkan untuk meningkatkan persepsi risiko staff Proyek Z PT. X.

\section{KESIMPULAN}

Berdasarkan hasil penelitian ini telah didapatkan gambaran faktor-faktor yang membentuk persepsi risiko pada staff Proyek Z PT. X, kesimpulannya untuk masing-masing faktor masih belum menunjukan nilai yang baik untuk membentuk persepsi risiko, namun yang jadi perhatian untuk dimensi risk perceived adalah faktor common dread yang didapatkan terdapat $65 \%$ staff Proyek Z tidak takut menghadapi risiko yang pada pekerjaan dan faktor catastrophic potential dengan 65\% staff Proyek $\mathrm{Z}$ merasa bahwa risiko yang ada pekerjaan konstruksi bersifat kronik. Untuk dimensi sosial dan budaya yang menjadi perhatian adalah faktor organization, didapatkan terdapat $60 \%$ staff Proyek $\mathrm{Z}$ menganggap bahwa peran organisasi kurang baik untuk meningkatkan persepsi risiko staff Proyek 
Z. Manajemen Proyek Z dapat memperhatikan saran-saran yang diberikan berdasarkan hasil analisis yang telah dijelaskan pada masing-masing faktor, untuk skala prioritas manajemen Proyek Z dapat mempertimbangkan faktor yang menjadi prioritas untuk diperbaiki yaitu faktor common dread, catastrophic potential, dan Organization. Sehingga staff Proyek $\mathrm{Z}$ dapat menjadi role model untuk para pekerja untuk mencegah terjadinya kecelakaan kerja. Studi ini dapat dilanjutkan untuk melihat apakah faktorfaktor yang membentuk persepsi risiko ini memiliki hubungan yang signifikan dengan persepsi risiko.

\section{UCAPAN TERIMA KASIH}

Peneliti mengucapkan terima kasih kepada semua pihak yang telah membantu jalannya penelitian ini

\section{DAFTAR PUSTAKA}

Albert, A., Hallowell, M. R., Kleiner, B., Chen, A., \& Golparvar-Fard, M. (2014). Enhancing Construction Hazard Recognition with HighFidelity Augmented Virtuality. Journal of Construction Engineering and Management, 140(7), 04014024. https://doi.org/10.1061/(asce)co.1943 $-7862.0000860$

Alomari, K. A., Gambatese, J. A., \& Tymvios, N. (2018). Risk Perception Comparison among Construction Safety Professionals: Delphi Perspective. Journal of Construction Engineering and Management, 144(12), 04018107. https://doi.org/10.1061/(asce)co.1943 $-7862.0001565$

Carrillo, P., \& Chinowsky, P. (2006). Exploiting Knowledge Management: The Engineering and Construction Perspective. Journal of Management in Engineering, 22(1), 2-10. https://doi.org/10.1061/(asce)0742597x(2006)22:1(2)

Chaswa, E. N., Kosamu, I. B. M.,
Kumwenda, S., \& Utembe, W. (2020). Risk perception and its influencing factors among construction workers in Malawi. Safety, 6(2), 1-12. https://doi.org/10.3390/safety602003 3

Guertler, C., Speck, G. M., Rezende, P. C., Vergara, L. G. L., \& Seiffert, W. Q. (2021). Occupational risk perception in mollusk farm workers. Safety Science, 135(June 2020), 105102. https://doi.org/10.1016/j.ssci.2020.10 5102

Haslam, R. A., Hide, S. A., Gibb, A. G. F., Gyi, D. E., Pavitt, T., Atkinson, S., \& Duff, A. R. (2005). Contributing factors in construction accidents. Applied Ergonomics, $36(4$ SPEC. ISS.), 401-415. https://doi.org/10.1016/j.apergo.2004. 12.002

Holmes, N., Lingard, H., Yesilyurt, Z., \& De Munk, F. (1999). An Exploratory Study of Meanings of Risk Control for Long Term and Acute Effect Occupational Health and Safety Risks in Small Business Construction Firms. Journal of Safety Research, 30(4), 251-261.

https://doi.org/10.1016/S0022-

4375(99)00020-1

Loewenstein, G. F., Hsee, C. K., Weber, E. U., \& Welch, N. (2001). Risk as Feelings. Psychological Bulletin, 127(2), 267-286. https://doi.org/10.1037/00332909.127.2.267

Maqsood, T. (2015). The Role of Knowledge Management in Supporting Innovation and Learning in Construction The Role of Knowledge Management in Supporting Innovation and Learning in Construction A tAhesis submitted in fulfilment of the requirements for the degree of Doctor of . January 2006.

Martin, H., \& Lewis, T. M. (2014). Pinpointing Safety Leadership Factors for Safe Construction Sites in Trinidad and Tobago. Journal of Construction 
Engineering and Management, 140(2), 04013046. https://doi.org/10.1061/(asce)co.1943 $-7862.0000795$

McGonagle, A. K., \& Kath, L. M. (2010). Work-safety tension, perceived risk, and worker injuries: A mesomediational model. Journal of Safety Research, 41(6), 475-479. https://doi.org/10.1016/j.jsr.2010.09.0 02

Namian, M., Albert, A., Zuluaga, C. M., \& Behm, M. (2016). Role of Safety Training: Impact on Hazard Recognition and Safety Risk Perception. Journal of Construction Engineering and Management, 142(12), 04016073. https://doi.org/10.1061/(asce)co.1943 $-7862.0001198$

PSYCHOLOGICAL ANTECEDENTS OF RISK-TAKING BEHAVIOR IN CONSTRUCTION by Antoine JeanPierre Tixier University of Colorado, 2013 A thesis submitted to the Faculty of the Graduate School of the University of Colorado in partial fulfillment of the requirements. (2013).

Schmidt, M. R. (2004). Investigating Risk Perception: A Short Introduction. Loss of Agro-Biodiversity in Vavilov Centers, with a Special Focus on the Risks of Genetically Modified Organisms GMOs, October, 1-16. http://www.markusschmidt.eu/pdf/Int ro_risk_perception_Schmidt.pdf

Shin, M., Lee, H. S., Park, M., Moon, M., \& Han, S. (2014). A system dynamics approach for modeling construction workers' safety attitudes and behaviors. Accident Analysis and Prevention, 68, 95-105. https://doi.org/10.1016/j.aap.2013.09. 019

Sjöberg, L., Moen, E., \& Rundmo, T. (2004). of the psychometric Explaining risk. In An evaluation of the psychometric paradigm in risk perception research (Vol. 2, Issue 2). http://66.102.9.104/search?q=cache: $x$ 8G44WOi3ssJ:www.svt.ntnu.no/psy/ Torbjorn.Rundmo/Psychometric_para digm.pdf+Explaining+risk+perceptio n. \&hl $=$ en $\& \mathrm{ct}=\mathrm{clnk} \& \mathrm{~cd}=3 \& \mathrm{gl}=\mathrm{uk}$

Slovic, P., Fischhoff, B., \& Lichtenstein, S. (1980). Judgmental Biases in Risk Perceptions. Perceived Risk: Psychological Factors and Social Implications, 1-13.

Slovic, P., \& Weber, E. U. (2002). Perception of risk posed by extreme events. Risk Management Strategies in an Uncertain World, 1-21.

Starr, C. (2020). Social Benefit Versus Technological Risk: What is Our Society Willing to Pay for Safety? Renewable Energy, 165, 136-152. https://doi.org/10.4324/97813157932 45-125

Wilson, R. S., Zwickle, A., \& Walpole, H. (2019). Developing a Broadly Applicable Measure of Risk Perception. Risk Analysis, 39(4), 777791.

https://doi.org/10.1111/risa.13207 